\title{
MICROSTRUCTURAL CHARACTERIZATION OF Ag-SHEATHED TI-Ba-Ca-Cu-O AND Bi-Sr-Ca-Cu-O SUPERCONDUCTING TAPES BY ANALYTICAL ELECTRON MICROSCOPY*
}

\author{
J.G. Hu, D.J. Miller, K.C. Goretta, and R.B. Poeppel \\ Science \& Technology Center for Superconductivity \\ Materials Science Division \\ Materials and Components Technology Division \\ Argonne National Laboratory, Argonne, Illinois 60439
}

\begin{abstract}
The submitted manuscript has been authored
by a contractor of the U.S. Government under

contract No. W-31-109-ENG-38. Accordingly,

the U.S. Government retains a nonexclusive,

royalty-tree llcense to publish or reproduse the

published form of this contribution, or allow

others to do so, for U.S. Government purposes.
\end{abstract}

1992 Applied Superconductivity Conference, August 24-28, 1992, Chicago, IL

$\mathrm{jmc}$

DISCLAIMER

This report was prepared as an account of work sponsored by an agency of the United States Government. Neither the United States Gnvernment nor any agency thereof, nor any of their employees, makes any warranty, express or implied, or assumes any legal liability or responsibility for the accuracy, completeness, or usefulness of any information, apparatus, product, or process disclosed, or represents that its use would not infringe privately owned rights. Reference herein to any specific commercial product, process, or service by trade name, trademark, manufacturer, or otherwise does not necessarily constitute or imply its endorsement, recommendation, or favoring by the United States Government or any agency thereof. The views and opinions of authors expressed herein do not necessarily state or reflect those of the United States Government or any agency thereof.

*Work supported by the U.S. Department of Energy, Division of Basic Energy Sciences-Materials Sciences and Superconductivity Pilot Center under contract \#W-31-109-ENG-38 (DJM, KCG, RBP) and the National Science Fondation Office of Science and Technology Center for Superconductivity contract \#DMR-8809854 (JG). 


\title{
Microstructural Characterization of Ag-Sheathed Tl-Ba-Ca-Cu-O and Bi-Sr-Ca-Cu-O \\ Superconducting Tapes by Analytical Electron Microscopy
}

\author{
J. G. Hu, D. J. Miller, K. C. Gorelti, and R. B. Poeppel
}

Argonne National Laboratory

Argonne, Illinois 60439

\begin{abstract}
The microstructures of $\mathrm{ml}(1223)$ and $\mathrm{Pb}$-doped $\mathrm{Bi}(2223)$ silver tapes produced by the powder-in-tube (PIT) method have been examined by scanning electron microscopy (SEM), transmission electron microscopy (TEM) and energy dispersive spectrometry (EDS). The T1 tapes annealed below the melting point exhibited fine grains and a high density of pores while tapes subjected to partial melting prior to solid state annealing were fully dense with large grains. However, these tapes also showed an increase in the size and density of impurity particles, particularly $\mathrm{CaO}$ and a $\mathrm{Ba}-\mathrm{Cu}$ rich phase. Silver powders added to the precursors tended to promote the growth of $\mathrm{Tl}(1223)$ at lower temperatures but also interfered with the development of texture by providing nucleation sites of random orientations. In contrast, the $\mathrm{Bi}(2223)$ tape exhibited a high degree of texture and alignment. The incorporation of silver within the superconducting phase was found to be negligible for both the $\mathrm{Tl}(1223)$ and $\mathrm{Bi}(2223)$ tapes.
\end{abstract}

\section{INTRODUCTION}

Significant efforts have been directed towards the development of silver-sheathed high temperature superconductor tapes and wires for a variety of practical applications.. Due to the relatively poor mechanical properties of $Y$-based superconductors, more recent efforts have concentrated on wires and tapes of $\mathrm{Bi}$ - and $\mathrm{Tl}$-based superconductors. However, both the $\mathrm{Bi}$ - and $\mathrm{Tl}$-based superconductors are highly anisotropic, with highest critical currents along the $a-b$ planes. $[1,2]$ In addition, these superconductors suffer from weak coupling across grain boundaries which severely limits current flow in polycrystalline materials. $[3,4,5,6]$ Therefore, it is highly desirable to have well aligned grains whose $a-b$ planes lie parallel to the tape surface, i.e. parallel to the direction current flow. Another factor which may limit current flow is the presence of non-superconducting impurity phases and voids. The presence of these defects may serve to limit current flow in two ways. Firstly, they may interfere with grain growth, offsetting efforts to achieve grain alignment or texture. Secondly, they may limit the critical current carried by a wire as a result of a decreased cross-sectional area of superconductor. Therefore it is also of significant benefit to minimize the volume fraction of these defects.

The $\mathrm{Tl}(1223)$ superconductor has a higher transition

Research supported by the U.S.D.O.E., Divisions of Basic Energy Sciences-Materials Sciences and Superconductivity Pilot Center under contract \#W-31-109-ENG-38, and the NSF. Office of Science and Technology Centers under contract \#STC8809854. Manuscript received August 24. 1992. temperature than Bi-based superconductors. In addition, due to a higher irreversibility line, $\mathrm{TI}(1223)$ is more suitable to high magnetic field applications at temperatures above $20 \mathrm{~K}$ due to stronger coupling between $\mathrm{Cu}-\mathrm{O}$ layers.[7] To date, however, although considerable attention has been focused on $\mathrm{Ag}$-sheathed $\mathrm{Bi}-\mathrm{Sr}-\mathrm{Ca}-\mathrm{Cu}-\mathrm{O}$ superconducting tapes, little has been published on Tl-based superconducting tapes in spite of these potential advantages. In this work, $\mathrm{Ag}$ has been added to the superconducting powders to lower the melting point and yield a micro-composite in an effort to improve mechanical properties of the tapes.[8,9] In this paper we report on studies of the microstructures of $\mathrm{Tl}(1223)$ tapes processed with and without partial melting prior to solid state sintering. The role of $\mathrm{Ag}$ in the development of microstructure of the $\mathrm{Tl}(1223)$ tapes has also been investigated, and the results are compared with those obtained from the $\mathrm{Bi}(2223)$ tape.

\section{EXPERIMENTAL PROCEDURE}

The $\mathrm{Tl}$ and $\mathrm{Bi}$ tapes were fabricated by a powder-in-tube technique which has been described in more detail elsewhere. $[10,11]$ In brief, powders of the appropriate superconducting phase were loaded into $6.35 \mathrm{~mm}$ outer diameter closed-end tubes and packed by vibration and ramming to increase the packing density. The loaded tubes were evacuated, sealed, and then drawn at $\approx 15 \%$ reduction per pass with an intermediate anneal at $260^{\circ} \mathrm{C}$ for 20 minutes every third pass to a diameter of $1.8 \mathrm{~mm}$. The tubes were then rolled at $\approx 10 \%$ reduction per pass to a final thickness of $\approx 450 \mu \mathrm{m}$. The $\operatorname{Tl}(1223)$ tapes were annealed in oxygen according to two schedules. One set of tapes was annealed at $850^{\circ} \mathrm{C}$ for 36 hours while the other was heat treated at $895^{\circ} \mathrm{C}$ for 6 minutes to achieve partial melting and then held at $845^{\circ} \mathrm{C}$ for 2 hours. The $\mathrm{Bi}$ tape was first annealed at $890^{\circ} \mathrm{C}$ for one and a half hours to achieve partial melting followed by annealing at $840^{\circ} \mathrm{C}$ for 100 hours, both treatments in air.

Samples were prepared for SEM observation using standard metallographic techniques. Isopropyl alcohol was used for cleaning in between steps to avoid any possible reaction with water. In the SEM, backscattered electron imaging was used extensively for enhanced sensitivity to composition. Crosssectional samples were prepared for TEM by grinding flat the outer surface of the tape and then sandwiching the cleaned tape between $\mathrm{Al}_{2} \mathrm{O}_{3}$ using $\mathrm{M}$-bond 610 epoxy. After encapsulating the sandwich in a $3 \mathrm{~mm}$ O.D. tube, TEM samples were prepared using standard techniques involving slicing, grinding, and dimpling. Final thinning to perforation was carried out by ion milling using $4 \mathrm{kV}$ Ar ions while maintaining the sample at liquid nitrogen temperature. TEM and EDS were carried out using Philips EM+20 and CM 30 microscopes operated at $100 \mathrm{kV}$ and $300 \mathrm{kV}$ respectively. 


\section{RESLLTS AND DISCUSSION}

The microstructure of the Tl(1223) tape annealed at $850^{\circ} \mathrm{C}$ without partial melting is shown in the backscattered electron micrograph of Fig. 1. The micrograph, which shows the interior of the lape, shows several different impurity phases, which appear dark gray or black, together with the Ti(1223) phase, which is gray, and silver particles, which are light. In aldition, the tape has a high density of pores, which appear black, indicating incomplete sintering and densification. A higher temperature and/or longer annealing period is needed to climinate the pores. The dominant impurity phases observed are $\mathrm{CaO}$ and a $\mathrm{Ba}-\mathrm{Cu}$ rich phase. A lesser amount of a $\mathrm{Ca}-\mathrm{Cu}$ phase was observed. Perhaps most significant is the small grain size and poor connectivity of the Tl(1223) grains.

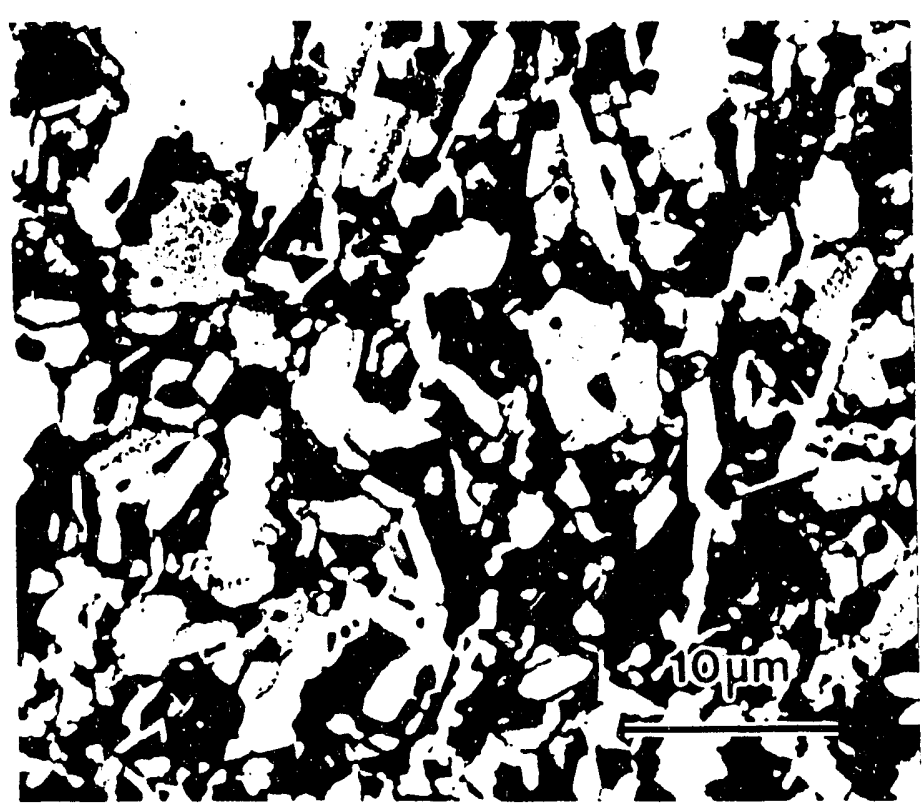

Fig. 1 SEM backscattered electron micrograph of the $\mathrm{Tl}(1223)$ tape annealed in the solid state at $850^{\circ} \mathrm{C}$ for 36 hours.

In contrast, the $T 1$ (1223) tape that had been subjected to partial melting by heating to $895^{\circ} \mathrm{C}$ prior to solid state sintering appeared to be fully dense with large, well-connected Tl(1223) grains, as shown in Fig. 2. It seems likely that partial melting during the initial high temperature anneal allows liquid to fill void space and enhance sintering kinetics. However, a high fraction of $\mathrm{CaO}$ phase (black) and a $\mathrm{Ba}-\mathrm{Cu}$ rich phase (dark gray) were also observed. In addition very small amount of $\mathrm{CuO}$ and a $\mathrm{Ca}-\mathrm{Cu}$ rich phase were also obstrved. The impurity phases typically exist as discrete particles and are more or less uniformly distributed throughout the sample, including along the Ag interface. In addition, all of the impurity phases observed were found to be much larger than in the tape processed without partial melting. Thus, although the effect of partial melting appears to be beneficial in terms of increasing density and promoting the growth of large, connected $\mathrm{Tl}(1223)$ grains, there are some potential drawbacks related to the precipitation and growth of impurity phisies.

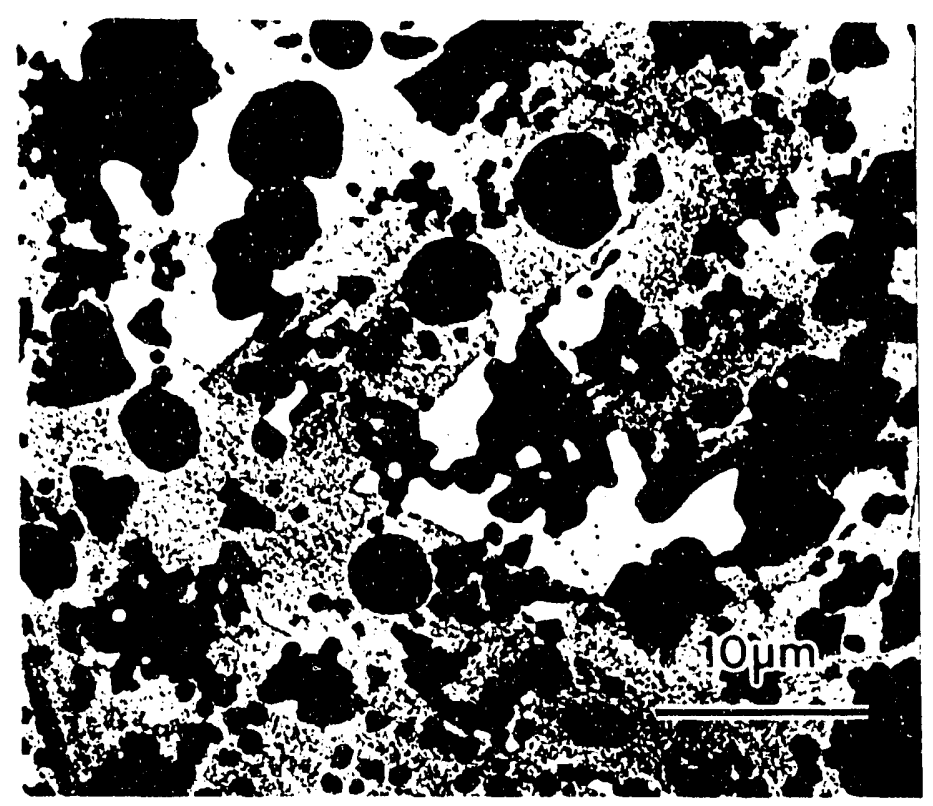

Fig. 2 SEM backscattered electron micrograph of the TI(1223) tape subjected to partial melting at $895^{\circ} \mathrm{C}$ for 6 minutes prior to sintering at $845^{\circ} \mathrm{C}$ for 2 hours.

Silver particles were intentionally added to the precursor powders in order to improve the mechanical properties of the tapes and to lower the melting point of $\mathrm{Tl}(1223)$ in order to promote grain growth. However, the role these silver additions play in the development of microstructure is somewhat ambiguous. Both superconducting and impurity phases were observed to be in contact with silver in each tape. SEM showed a higher proportion of Tl(1223) grains to have nucleated along the silver particles in the case of the samples annealed without partial melting. In addition, the $T l(1223)$ grains along these silver particles were much larger. For example, Fig. 3 is an SEM backscattered electron image collected from the $\Gamma l$ tape that had been annealed without

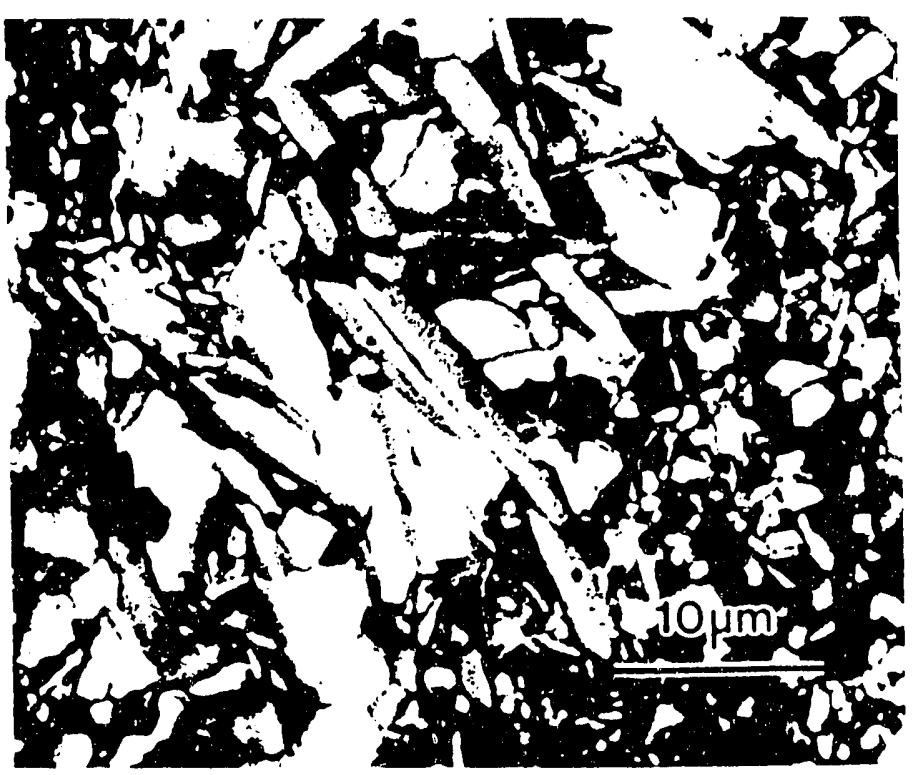

Fig. 3 The Tl tupe sintered at $850^{\circ} \mathrm{C}$ for 36 hours. The Tl(1223) grains adjacent to the silver particles (white) are larger than in other areas. 


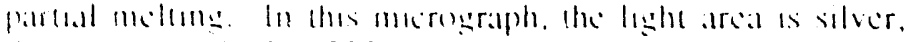

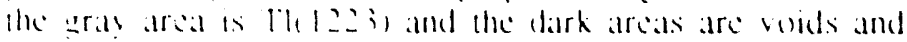

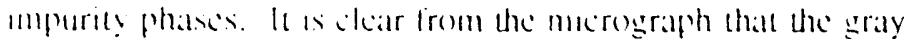
ll1.2. i grams in conlace with the silver are much larger than

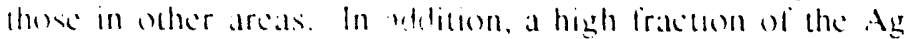
merlace is in entale with Th(1223) whereals only a small fraction is oceupied by impurities. Similar cilects are ohicrved along the $\mathrm{Ag}$ interfice of the sheath. although the Th(122.) layer is irefulently very thin.

These results suggest that silver does promote the growth of Tl(1223) grains. However, silver may also prevent the coalescence and hence the connectivity of grains. Furthermore, the random orientations and distribution of the Ag particles and their irregular shapes may render the alignment of grains impossible. For example, Fig. $t$ is a TE.W micrograph which shows a high angle grain boundary in the lape processed without partial melting. The a-h planes of both grains are parallel to the surfaces of a silver particle. Although this feature may be suggestive of favorable nucleation on the $A g$ surface, it also results in a high angle grain boundary since it is likely that the angle between the two grains is defined by the angle between the two surfaces of the silver particle. Nevertheless, it is still unclear whether the Tl(1223) nucleates directly on the Ag surfaces. The lape subjected to partial melting exhibited a more random distribution of $\mathrm{Tl}(1223)$ grains and impurity phases along the Ag interfaces. In addition, as shown in the TEM micrograph of Fig. 5, some Tl(1223) grains were found to orient randomly with respect to the $\mathrm{Ag}$ interface, although it is possible that this grain may have nucleated at some other point at which it was more highly aligned. Typically, for both $\mathrm{Bi}$ - and Tl-based lapes, the Ag interface is not perfectly smooth, and HTS grairs which appear to be aligned at one point can be misaligned with respect to the interface at another point.

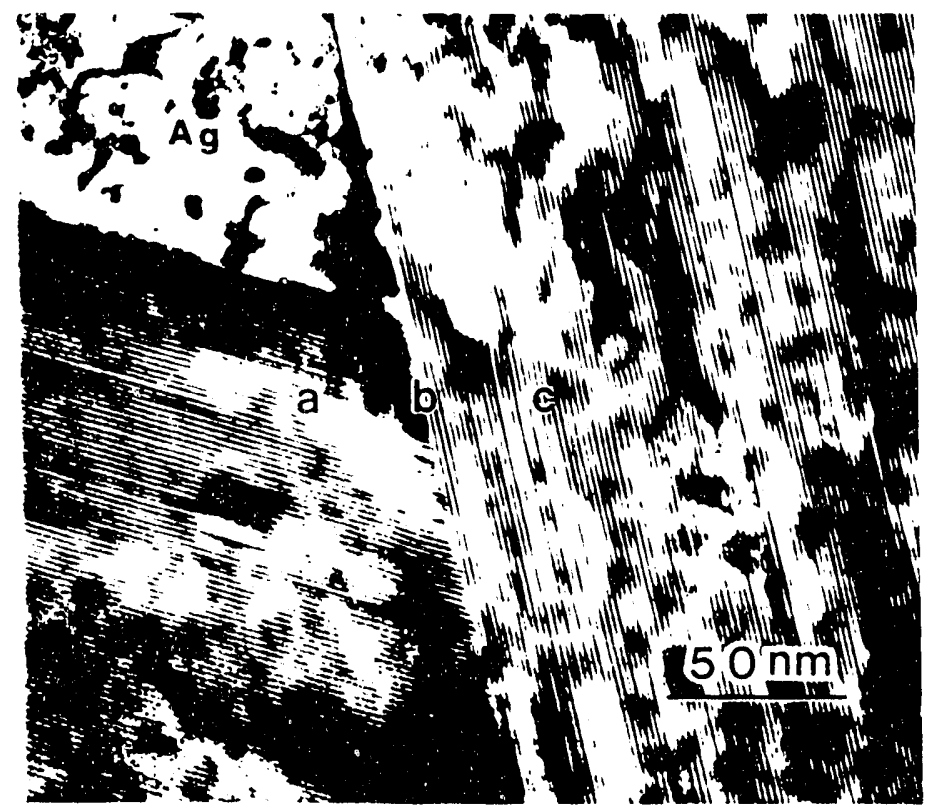

Fig. - TEM micrograph of a high angle srain busudary in the Tl(1223) tape anncaled in the solld state at $8500 \mathrm{C}$ for 36 hours.

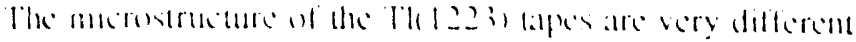

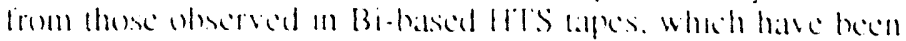
ituded an some detail.|12.1.il As shown an the TEM marograph of lig. 6, these tapes are charaterised hy colonics of highly aligmed domalns. Aluhough calch colony may bo separated by a high angle grain boundary, the domains, which

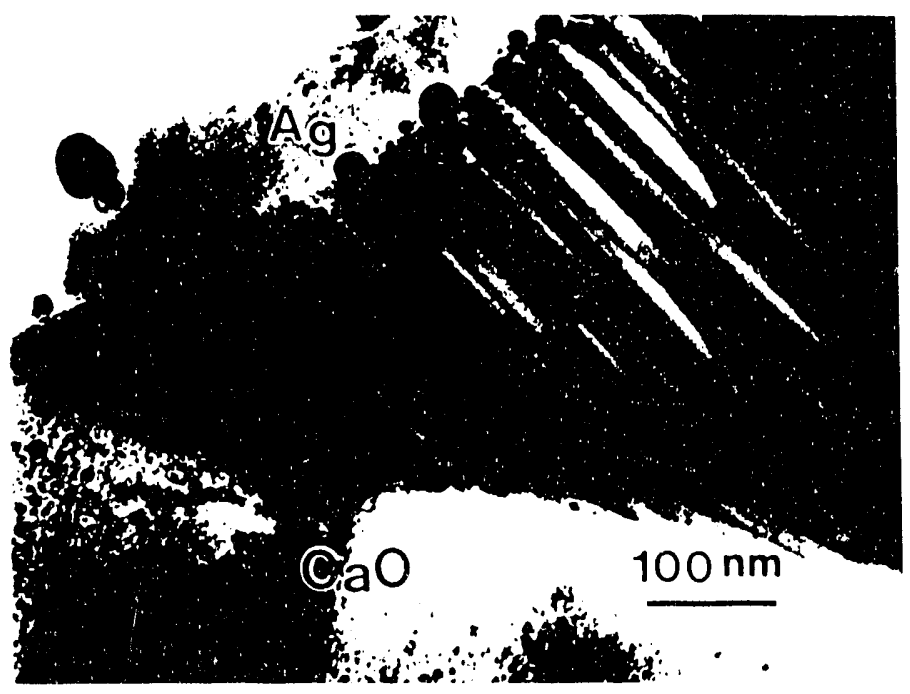

Fig. 5 TEM micrograph of a Tl(1223) grain randomly oricnted with respect to Ag interface.

may be microns thick, are separaled by low angle grain boundaries (a lew degrees). Al silver interfaces the plates are parallel to the interface within a few degrees, and grains which are highly misaligned with the silver are rarely observed. In the TI(1223) samples, on the other hand, both aligned and misaligned grains are observed, as shown above. Luo et. al. [13] suggested that BSCCO phase growth is two dimensional. The non-plate like morphology of $\mathrm{TI}$ lapes may indicate a three dimensional growth mechanism. In light of the high degree of anisotropy exhibited by both the $\mathrm{Tl}$ - and Bi-based superconductors, however, it is difficult to resolve the basis for these diflerent growth mechanisms. In lact, most of our recent work on polycrystalline thin films of $\mathrm{Tl}(1223)$ on $\mathrm{ZrO}_{2}$ shows that grains are plate-like with small angles between plates. Thus, although the data above suggests that Ag promotes the growth of the $T l(1223)$ phase, the alignment of grains is viewed as a nucleation and growth phenomenon and is the subject of lurther study. For example, it is possible that the growth mechanism is allered in the presence of silver. Future eflorts will be amed at resolving this issue in order 10 develop a plate-like microstructure in Tl tapes.

Finally, the incorporation of Ag into the Tli 1223 ) phatio was axamined by EDS. Spectra were collecked irom the points labcled $(a),(b)$ and $(c)$ in Fig. t, and these spectra are ploted in Fig. 7. The sitver peak is small and of the same intensil: in each spectrum, indicating no sergeration of $A-10$ the srain boundary. Furthermore, the how imensity of the As peith is approximately the same as that recorded during an in-hole

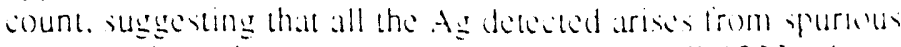

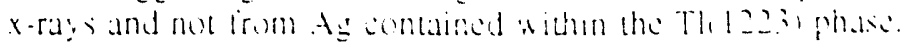

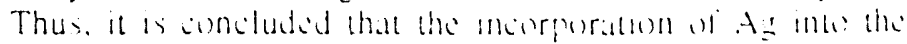
Th1223 phasic ansoligike. 


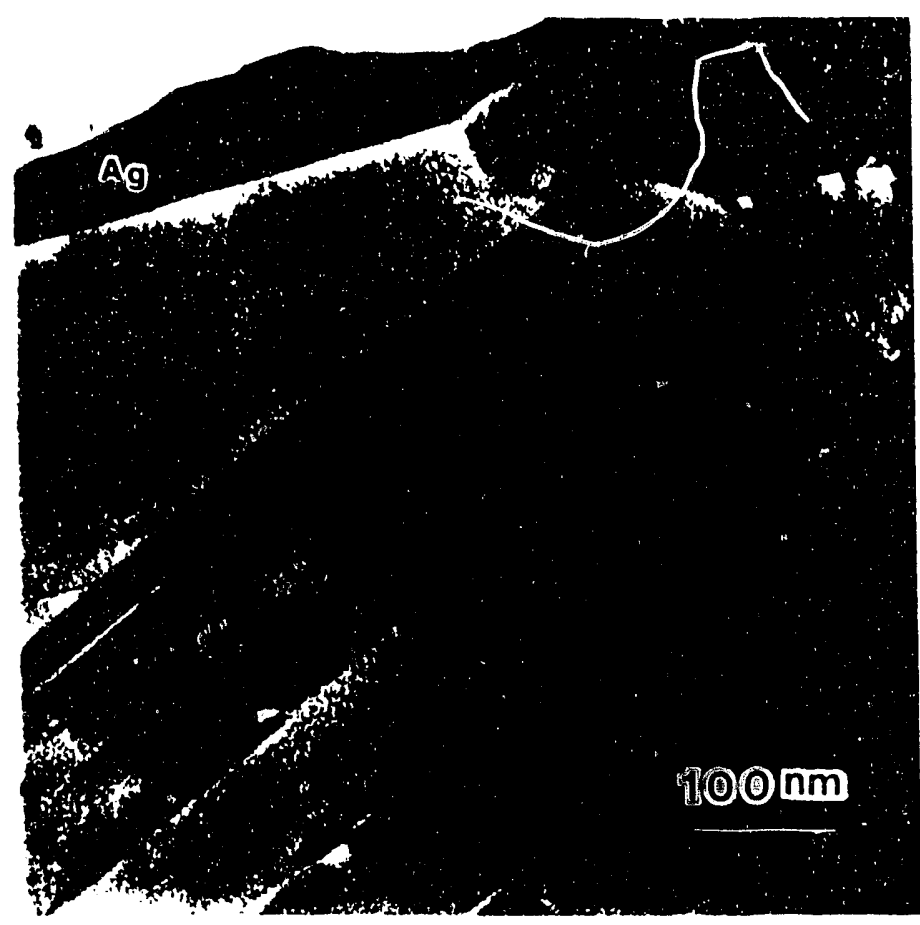

Fig. 6 TEM micrograph showing the morphology of the Bi(2223) tape.

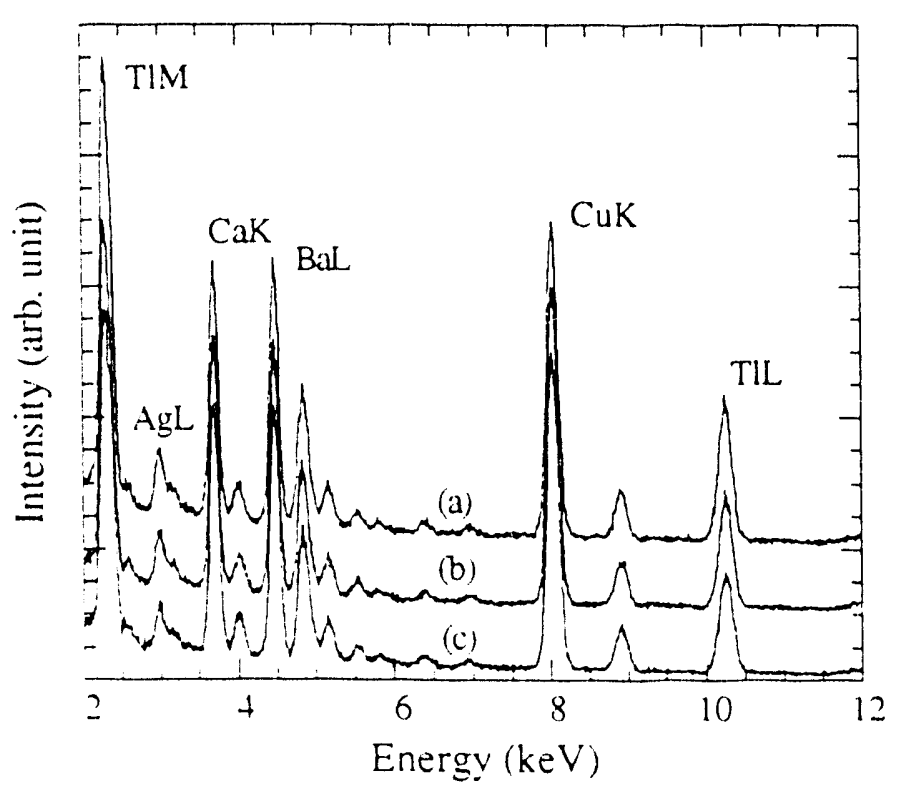

Fig. 7 EDS spectra collected from the points labeled (a), (b) and $(c)$ in Fig. 4.

\section{SLMMARY}

The microstructures of Ag sheathed Tl(1223) tapes and Pbdoped B1122231 upes have been investigated by SEM. TE.M and EDS. The TI tapes sintered at $8+5^{\circ} \mathrm{C}$ for 36 hours contains pores and impurity phases within a matrix of fine. grained Tl(1223) grains. Tapes subjecked lo partial meltung at $895^{\circ} \mathrm{C}$ lor 6 minules followed by solid stall sinkering al $8+50$ showed signilicantly reduced porosily and a larger grain size. Silver addicions cended to promete the growth of the Tl(1223) phase, presumably by lowering the melting point and providing lavorable nucleation sitcs, but also made alignment of grains more diflicult dac (o) the random distribution and orientation of silver particles. Both superconducting and impurity phases form at silver which makes it difficult to minimize the amount of impurity phases. In contrast to the $\mathrm{Bi}(2223)$ lape, in which the superconduc!ing grains are well aligned, the grains in Tl lapes have irregular shapes and are randomly oriented.

\section{REFERENCES}

[1] L. Schulu, B. Raos, P. Schmilt, P. Kummeth and G. Saemann-Ischenko, IEEE Trans. Magn., MAG, vol. 27, pp.990-996, Feb., 1991.

[2] J. H. Kang, K. E. Gray, R. T. Kampwirth and D. W. Day, Appl. Phys. Lett. vol. 53, pp. 2560-2562, Dec., 1988.

[3) S Jin, R. B. van Dover, T. H. Tiefel, J. E. Gracbnar, N. D. Spencer, Appl. Phys. Let., 58 (8), pp. 868-870, Feb., 1991.

[4] J. E. Tkaczyk, R. H. Arendt, M. F. Garbauskas, H. R. Hart, K. W. Lay, F. E. Luborsky, Phys. Rev. B, 45 (21), pp. 12506-12511, June, 1992.

[5] M. Huth, M. Schmitt, H. Adrian, Physica C. 178, pp. 203-212, 1991.

[6] A. C. Wright, K. Zhang, A. Erbil, Phys. Rev. B. 44 (2), pp. 863-866, July, 1991.

[7] D. H. Kim, K. E. Gray, R. T. Kampwirth, J. C. Smith, D. S. Richeson, T. J. Marks, J. H. Kang, J. Talvacchio and M. Eddy, Physica C 177, pp. 431-437, July, 1991.

[81 G.J. Yurck, J.B. Vander Sande, W.-X Wang, D.A. Rudman, Y. Zhang and M.M. Matthiesen, Metall. Trans. vol. 18A, pp. 1813-1817, Oct., 1987.

[9j K. Matsuzaki, A. Inoue and T. Masumoto, Jpn. J. Appl. Phys. vol. 27 pp. L195-L198, Feb., 1988.

\10] C.-T. Wu, K. C. Goretta and R. B. Pocppel, Applied Superconductivity vol. 1 (in press).

[11] K. C. Gorella, C.-T. Wu, M. T. Lanagan, M. A. Boling, Donglu Shi, D. J. Miller, Nan Chen, W. G. Hanewald, S. Sengupta, Z. Wang, R. P. Poeppel, F. Foong and S. H. Licu, Proc. 1992 Spring Viceting of MRS, San Francisco, CA.

[12] Y.Feng, K. E. Hautanen, Y. E. High, D. C. Larbalesticr, R. Ray II, E. E. Hellstrom and S. E. Babcock, Physica C (submitted).

[13] J. S. Luo, N. Merchant, V. A. Maroni, D. M. Gruen. B. S. Tani, W. L. Carter, G. V. Riley, Jr. and K. H. Sandhage, Applied Physics Lellers (submilled). 

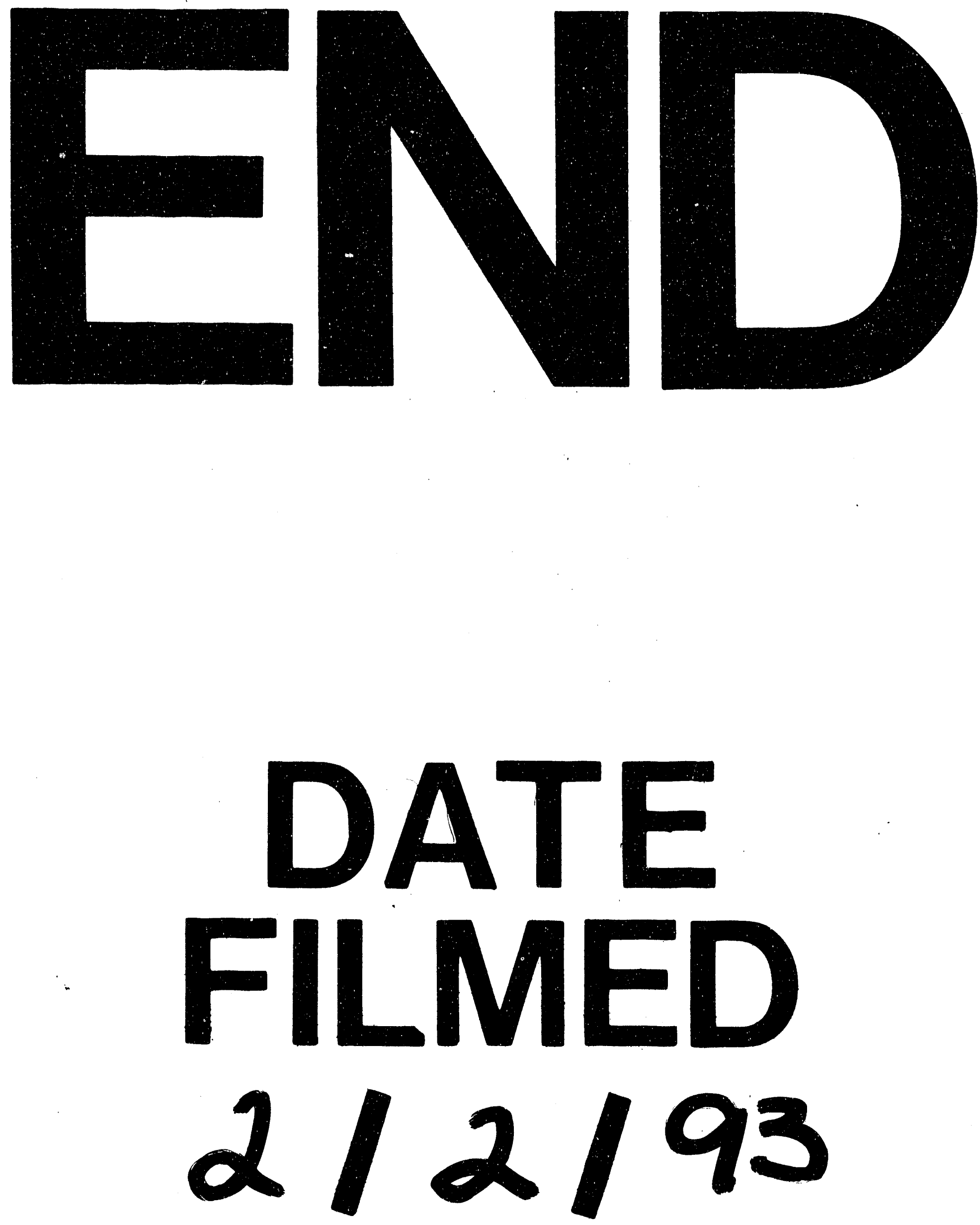
